\title{
Alianzas y coaliciones germánicas en el reino visigodo de Toulouse (siglo $v$ )
}

Ana M. ${ }^{A}$ Jiménez Garnica *

Las Navidades del a. 406 supusieron un peligro mucho más grave para el Imperio Romano de Occidente que la simple irrupción masiva, en el interior de sus límites, de unas bandas de bárbaros hambrientos. Los diferentes grupos estaban viviendo en estos momentos un proceso de rápida evolución interna que, entre otros matices, suponía su organización en torno a una autoridad monárquica fuerte que se encargara de proporcionarles un territorio propio y estable. Como recoge Teillet ${ }^{1}$, en esta quinta centuria de nuestra era se estaban conformando las futuras naciones de la Europa Moderna. Aunque los diferentes pueblos no se encontraban en el mismo estadio evolutivo, ni pertenecían tampoco a las mismas etnias y culturas, los más poderosos formaron coaliciones con miras a obtener su libertad y defender su individualismo frente al Imperio. Éste, sin embargo, no quiso o no supo entenderlo así e, ignorando que algunos de ellos estaban alcanzando una nueva realidad jurídico-política designada como Estado ${ }^{2}$, intentó mantener un sistema coherente y, sobre todo, unificado de administración civil y militar, con lo que no consiguió sino precipitar su propia ruina. Hacía ya algunos años de la división administrativa teodosiana en Pars Orientis y Pars Occidentis (a. 395), pese a la cual en el interior del Imperio permanecia viva la idea de una eternidad espacio-temporal. Sólo cuando fue evidente que parte de ese

* I.N.B. «Beatriz Galindo".

' S. TEILLeT, Des Goths à la nation gothique. Les origines de lidée de nation en Occident du V au VIr siecle, Paris 1984, pág. 4.

2 S. TEILLET, Ibidem. 
espacio había quedado sustraído a su autoridad, los ciudadanos de Occidente aceptaron entonces la realidad de la caída del Imperio Romano.

Debemos descartar la idea, con éxito durante bastante tiempo, de que las alianzas germánicas estuvieran animadas por pensamientos nacionalistas o étnicos de unidad frente a los romanos o a cualquier otro elemento de presión externa. Sabemos que estos pueblos venian enfrentándose entre sí desde fechas remotas, con anterioridad a su penetración en el territorio del Imperio y cuando todavia no habían iniciado el proceso de aculturación que sufririan después (Jordanes, Gética, IV, 26; XVI, 89; XXII, 113-115; Panegyrici latini, III, II, 17, etc.) nos informan de las hostilidades mantenidas entre vándalos y visigodos, por citar un ejemplo ${ }^{3}$. Más tarde, y una vez ya instalados en el interior del Imperio, Roma empleó a los bárbaros a su servicio para que se contuvieran unos a otros, para despejar territorios invadidos por los propios germanos, así como también para hacer frente a usurpaciones imperiales.

Vamos a centrarnos, más en concreto, en el caso de los visigodos durante el siglo v. En el a. 416, cuando todavía eran un pueblo errante por tierras del nordeste hispano, buscador de un territorio donde poder asentarse, Honorio contrató los servicios militares de los hombres de Walia para que anularan a los alanos de la Lusitania y a los vándalos Silingos de la Bética ${ }^{4}$ (Hidacio, Chron. 60). Tras su derrota, la fuerza germánica en Hispania se concentró en manos de los vándalos Hasdingos y de los suevos, mientras que los visigodos recibieron, en compensación, el ansiado territorio en el sur de la Galia, en el que pudieron establecerse definitivamente con permiso para cultivar las dos terceras partes de las tierras que la aristocracia senatorial gala les había cedido en virtud del pacto de la hospitalitas. Asi terminó de desarrollarse entre ellos el concepto de Nación y pudo comenzar su primer estado monárquico ${ }^{5}$.

${ }^{3}$ Chr. Courtois, "Rapports entre Wisigoths et Vandales", I Gotti in Occidente, Settimane di Studio de Spoleto, 1956, págs. 499-507.

${ }^{4}$ Walia no se detuvo ni tan siquiera ante el propio rex gentis Vandalorum, Fredbalus, que fue hecho prisionero y entregado a Honorio (Cfr. Chr. Courtois, Les Vandales et l'Afrique, París 1955, pág. 51 y ss.) o ante el de los alanos, Addax, que recibió la muerte.

${ }^{5}$ S. TEILlet, (obra citada, nota 1, pág. 7) considera que fue en la España visigoda donde, por vez primera, una nación bárbara, entendida en el sentido romano negativo de la palabra en la época targo-imperial, se convirtió antes en una "nación” de la Europa moderna pero, yo considero más bien que, si bien fue entonces cuando el concepto se definió por escrito tanto en la obra de San Isidoro como en los cánones de los concilios toledanos, su gestación se hizo en el reino galo de Tolosa durante el siglo $\mathrm{v}$, cuando se produjo una relación especial entre el rex y su gens sobre un territorio propio. 
En los años siguientes el gobierno imperial optó por apoyar a los suevos de la Península, que debian de haber alcanzado cierto grado de entendimiento con la aristocracia local y, para ello, en el a. 420 el ejército imperial, mandado por el comes hispaniarum Asterio, obligó a los vándalos a levantar el cerco que tenían puesto a los suevos en los montes Nerbasios. Uno o dos años después, no se sabe con certeza si en el 421 o 422, llegó a Hispania el Magister militum Castino con un ejército mucho más importante que el que había comandado Asterio. Venía con él el ejército visigodo de Aquitania (Próspero, 1, 278) al que, con toda probabilidad, se habrian solicitado de nuevo sus servicios militares en cumplimiento del foedus firmado en el a. 418. Pero, cuentan Hidacio (Chron. 77-78) y Olimpiodoro (frag. 40) que los visigodos y su jefe, Teodorico I, le abandonaron, como también lo hizo el comes africae, Bonifacio, con lo que el ejército imperial quedó deshecho ${ }^{6}$. La supremacía de los suevos quedó consolidada de momento y el Emperador tuvo que pedir a los visigodos en varias ocasiones que intervinieran para contrarrestar su poder ${ }^{7}$. Sin duda consideraba a ambos pueblos de importancia y capacidad militar similares y, además, jugaba a su favor el que los reinos suevo y visigodo se encontraban próximos geográficamente y con posibilidades de comunicación, tanto a través de los pasos pirenaicos ${ }^{8}$, como mediante los puertos del Atlántico.

No obstante, el rey Teodorico I, haciendo uso de su reciente autonomía, no se limitó a intervenir sólo cuando el gobierno imperial se lo pidió. Al mismo tiempo, y por voluntad propia, fue tejiendo una red de alianzas con los suevos y los vándalos, los dos pueblos germánicos más importantes establecidos en la Pars Occidentis, para lo cual aprovechó, su prolífica paternidad. A una de sus hijas la casó en el a. 449 con

${ }^{6}$ P. de Palol, (Tarraco hispanovisigoda, Tarragona, 1953, pág. 68) ubicaba la batalla cerca de Tarragona, mientras que Chr, Coirtois (Les Vandales..., pág. 51) y Stein (Histoire du Bas-Empire, 1957, vol. II, pág. 275) siguiendo la información de Hidacio, lo hacian en el sur de la Península. El motivo de estas deserciones no está claro pero, probablemente, estén en relación con un momento de máxima tirantez en las relaciones entre Honorio y Gala Placidia, la cual acabó siendo desterrada por su hermanastro a comienzos del año siguiente (a. 423). Bonifacio era uno de los máximos valedores de Gala Placidia y de que su hijo Valentiniano fuera el sucesor de Honorio que nos los tenia. Los visigodos, que habian sido muy perseguidos por Honorio, se debían pensar, por su parte, que su suerte mejoraría en caso de que gobernara su antigua "reina". Incluso, un grupo de ellos formaba su guardia personal en Rávena.

${ }_{7}$ L. GaRCí MoReno, "Mérida y el reino visigodo de Tolosa (418-507)», Homenaje a Sáenz de Buruaga, Diputación Provincial de Badajoz, 1982, pág. 227-240.

${ }^{8} \mathrm{M}$. ROUCHE, "Les rélations transpyrénéennes du $\mathrm{V}^{\mathrm{e}}$ au VIII" siècle", Les communications dans la Peninsule Ibérique au Moyen Age, Colloque Pau 1980, Paris 1981, págs. 1315. 
Requiario, hijo y sucesor del rey suevo Rechila, y a la otra, con Hunerico, nijo del poderoso rey vándalo Genserico. Con ello no hacía sino continuar la línea iniciada por su antecesor, Walia, cuya hija se casó con un ¿noble? suevo y se convirtió en la madre del no menos noble y famoso Ricimer, hombre fuerte de Occidente entre 457 y 472 . También los hijos de Teodorico, siguiendo su ejemplo, continuaron la política aliancista del padre. Pese a que los datos son escuetos, fundamentalmente a falta de fuentes germánicas contemporáneas, que son las que más se hubieran interesado por el tema, sabemos, por ejemplo, que su hijo Eurico se casó con la princesa burgundia Ragnahilde. Los burgundios fueron uno de los últimos pueblos integrados en el sistema federativo romano pues no se les concedió el foedus hasta el año 458 , cuando se consiguió reunir en la Sapaudia a toda la gens burgundia completa, que anteriormente se encontraba dispersa entre las dos orillas del Rin ${ }^{9}$. En el caso de Eurico, y habida cuenta de la fecha de la firma del foedus de los burgundios, es muy probable que el compromiso matrimonial no lo decidiese Teodorico I, muerto en la batalla de los Campos Catalaúnicos del a. 451, y a la que Eurico no le acompañó en razón de su corta edad, sino Teodorico II, hermano mayor de Eurico y rey desde el a. 453 al 466 . Además, este matrimonio pudo haber sido consecuencia de la aproximación realizada con los burgundios de Gundovico a partir del a. 456.

De esta manera la situación, ya de por sí preponderante, que tenían los visigodos en la Pars Occidentis, se vio reforzada con sus vínculos con los suevos ubicados en el tercio noroeste de Hispania, con los vándalos, señores del norte de África y dueños de las aguas del Mediterráneo Occidental desde el a. 440, y con los burgundios, situados al este del reino de Tolosa. Ello en un momento en que todavía, teóricamente, todos dependian del Emperador.

Esta nueva política de alianzas germánicas, selladas mediante compromisos matrimoniales, comenzó a forjarse con el establecimiento de jefes con función militar permanente al frente de sus respectivas gentes, los cuales, perteneciendo a familias prestigiosas (los Balthos, los Hasdingos, etc) estaban superando las antiguas magistraturas gentilicias y consolidando la institución monárquica en los territorios en los que estaban asentados como Nación. Por eso, aunque Walia hizo un primer intento aliancista en el reino de Toulouse, quien realmente comenzó a hacer uso extensivo de la costumbre fue Teodoricol, el probable hijo del gran

${ }^{9}$ Cfr. H. Wolfram, "Die Aufnahme germanischen Völker ins Römerreich: aspekte und Konsequenzen", Settimane di studio de Spoleto, 1981, XXIX, 1983, págs. 87-117. 
Alarico ${ }^{10}$, decidido a mantener en el trono aquitano a la familia de los Balthos. No sabemos si Teodorico concibió un sistema sucesorio similar al del vándalo Genserico, pero es probable dada la similitud de lo que ocurrió en el trono de Tolosa con lo que el rey vándalo dejó establecido antes de morir. Sabemos por Jordanes (Gética, XXXIII) que el rey Genserico reunió a sus numerosos hijos y, para evitar que la ambición de reinar suscitara entre ellos disensiones, dispuso que debían sucederse de mayor a menor y a la muerte del mayor. Eso fue lo que ocurrió tras la defunción de Teodorico I, a quien siguieron en el trono, por orden de edad, sus hijos Turismundo, Teodorico $\|$ y Eurico, aunque no sin que mediaran conflictos entre ellos ${ }^{11}$. Hubo otro, Frederico, mayor que Eurico, que gozó con Teodorico ll de las más altas dignidades. En las apariciones públicas se colocaba al lado del rey (Sidonio Apolinar, Paneg. Avit. VIII, 430 y ss) y llegó a dirigir el grueso del ejército visigodo en la expe-

${ }^{10}$ La única noticia que tenemos acerca de la filiación de Teodorico I, nos la proporciona Sidonio Apolinar (Paneg. Avit. V.505) cuando habla de Alarico, auus de Teodorico ll quien, a su vez, era hijo de Teodorico I:

"quae noster pecavit avus, quem fuscat id unum, quod te Roma capit...".

Algunos críticos han considerado que la mención de este auus era una licencia poética que se habia permitido Sidonio, pero yo no lo creo así, pues el significado conceptual del término era claro incluso en la época tardo-imperial. Así lo demuestra el que San Isidoro en sus Etimologias escribiera (IX, 5, 9): "auus pater patris est", y (IX,6, 32): "patris mei pater mihi avus est'. Actualmente E. Benveniste (Vocabulario de las instituciones indoeuropeas, 1983, pág. 148 y ss.) ha demostrado con un estudio filotógico la veracidad del aserto isidoriano y aclara (pág. 149) que cuando se designa al abuelo materno los textos especifican auus maternus. También auus puede designar al hermano de la abuela materna, es decir al tío abuelo materno. De haber sido asi en el caso de Teodorico II, queda claro que, ni Teodorico I, ni el II, tenían nada que ver con Alarico pero entonces tampoco lendría sentido la referencia del culto Sidonio. Incluimos un pequeño gráfico con las dos posibles variantes del término:

1. abuelo abuela (auus)

padre consorte

2. abuelo

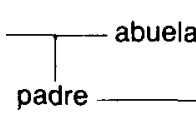
(1)

2. abuelo $\prod_{\text {padre }}$ abuela

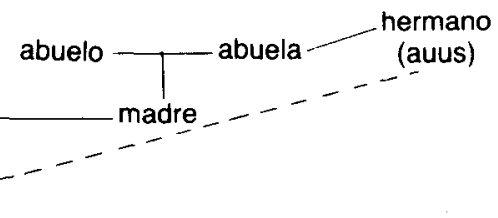

'Dice San Isidoro, cuando habla de la sucesión de Teodoricol (Mistoria Goth. 28), que "entre sus hijos se originaron grandes luchas por la obtención del reino". También sospechó del asesinato de Turismundo y de Teodorico II. 
dición a la Tarraconense en sustitución de su hermano, de tal manera, que en la Crónica de Mario, obispo de Avenches (Chron. 463), al informar de su muerte se le califica de rey. Iglesia Ferreiros ${ }^{12}$ plantea la posibilidad de que fuera un consortes regni pero, tal vez podríamos pensar mejor que su protagonismo político y militar se debía a que era él quien debía suceder, en razón de su edad, a Teodorico en el trono. En efecto, cuando Jordanes enumera a los hijos de Teodoricol (Getica$X X X V I)$ lo hace por orden cronológico, y dice que los dos mayores, Turismundo y Teodorico, acompañaron a su padre al enfrentamiento con Atila en 451, pero se quedaron en palacio, por su edad, Frederico, Eurico, Retemer e Himmerit. De los dos últimos no tenemos la más mínima noticia, tal vez a consecuencia de una muerte temprana. Por su parte, Frederico, gozó de gran predicamento entre los provinciales como se deduce de una carta del papa Hilario, enviada al obispo Leoncio de Arles, el 3 de noviembre de 462, en la que se canta su magnificencia.

Es curioso observar cómo Teodorico eligió a sus hijas, y no a los varones, para sellar los pactos con los dos pueblos germánicos entonces más poderosos, los suevos y los vándalos. Analizando sus posibles razones pensamos que una, bastante probable, haya que buscarla en una ancestral concepción estructural de la familia indoeuropea que establecía una relación especial de parentesco entre los hijos de las hijas y los hermanos varones de éstas, convertidos en auunculi de sus sobrinos ${ }^{13}$; con lo cual el rey visigodo se aseguraba que los pactos aliancistas se mantendrían entre su sucesor varón en el trono de Toulouse y los herederos de los reinos suevo y vándalo. Tácito recoge de forma muy gráfica esta costumbre entre los germanos (Germania, XX, 5):

"los hijos de la hermana reciben tantos cuidados de su tío como de su padre; hay quien piensa que este vínculo de sangre es más santo y estrecho" (sororum filiis idem apud auunculum qui ad patrem honor; quidam sanctionem artioremque hunc nexum sanguinis arbitrantur (...)").

En este sistema de parentesco, el padre de la madre no tiene ninguna importancia particular, mientras que si se tiene en cuenta tanto al

\footnotetext{
12 A. Iglesia Ferreiros, "Notas en torno a la sucesión al trono en el reino visigodo", Anuario de Historia del Derecho Español, XL, pág. 668.

${ }^{13}$ Cfr. E. Benveniste, Vocabulario de las instituciones indoeuropeas, pág. 152.
} 
padre del padre, dentro de la filiación agnática, como al hermano de la madre, en filiación uterina.

El reinado de Teodorico I (a. 418-451) coincidió cronológicamente con el emperador Valentiniano III (a. 425-455) y con la refencia legal de su madre Gala Placidia entre 425 y 437 . Ambos estuvieron a su vez dirigidos por Aecio, magister equitum per Gallias y diseñador de una nueva política de alianzas con la que procuró que los reinos bárbaros no desarrollaran sus afanes independentistas, ni se uniesen entre sí formando coaliciones, y que todos estuvieran al mismo tiempo en buenas relaciones con Rávena. Sin embargo, su línea política no sumó más que un cúmulo de fracasos ${ }^{14}$, y los que no resultaron tales, como la gran invasión de Atila a la Galia (a. 451), fue por la decisiva intervención de los pueblos germánicos, en concreto de los visigodos. Todo llevaba a sospechar que éstos se consideraban progresivamente independientes del gobierno central. La buena voluntad de Aecio chocó en primer lugar con los vándalos quienes hicieron gala de su plena autonomía rigiéndose por su propia era (iniciada en el a. 439 fecha de la toma de Cartago) y controlando el Mediterráneo. Valentiniano III no tuvo más remedio que conceder a Genserico el África Bizancena y la Proconsular para conseguir la paz. En la misma época se enfrentó a Teodorico I que se había empeñado en alcanzar la costa mediterránea, sin duda para coordinarse con los vándalos. También con él se vio obligado a firmar condiciones de paz y ampliar su territorio en la Galia con una parte de la Novempopulania (Salviano, De gub. Dei, VII, 7 y ss).

En los años siguientes Teodorico se comportó como un verdadero soberano, y debieron ser sus gestiones diplomáticas las que movieron a Aecio a recurrir al viejo procedimiento de colocar un pueblo de contención, en este caso a un grupo de alanos que, a partir del 440 , fueron establecidos entre los visigodos y los burgundios para contrapesar sus poderes y evitar posibles alianzas ${ }^{15}$. Como tal soberano, Teodorico recibió la visita en Toulouse del rey suevo Requiario ${ }^{16}$ en el 448 , y también

\footnotetext{
${ }_{14}$ Pese a todo contó con algunos admiradores, como Marcellinus que en su crónica (Chron. Min. II, 86) le considera "la gran salvación de la república de Occidente".

${ }^{15} \mathrm{Cfr}$. B. S. BACHRACH, "Another look at the Barbarian Settlement in Southern Gaul», Traditio, XXV, 1969, págs. 354-538, y Ibidem, A history of the alans in the West, Minneapolis, 1973 .

${ }_{16}$ Hay que tener en cuenta que en el sistema matrimonial germánico, el marido de la hija no contrae ningún vínculo con la familia de ésta, por lo que son escasos los términos para designar a los parientes de su mujer con los que no cohabita. Así, por ejemplo, en gótico existen términos para designar al padre y a la madre del marido ("Swaihra" y "Svaihro"), pero no para hacerlo con los de la mujer (cfr. E. BENVENISTE, obra citada, nota 11, pág. 163). Por tanto, Requiario no acudió a Toulouse a cumplir sus obligaciones familia-
} 
como tal actuó tres años después en el enfrentamiento de los Campos Catalaúnicos ${ }^{17}$. No obstante, esta política aliancista, tan finamente elaborada por Teodorico I, pasó por momentos de crisis. Previamente, en el a. 445, habian quedado rotas las relaciones entre la corte de Tolosa y la de Cartago cuando Genserico, que deseaba casar a su hijo Hunerico con Eudocia, hija del emperador Valentiniano III, acusó a su nuera visigoda de haberle querido envenenar $y$, después de haberle hecho mutilar las orejas y la nariz, la devolvió a su padre ${ }^{18}$. De esta manera Genserico, libre de sus compromisos con los visigodos, animó a Atila a que reclamara la Galia como dote matrimonial de Honoria, la hermana del Emperador, y anulara, así, el predominio de Teodorico I.

No sabemos cúal fue el "wergeld" que los vándalos tuvieron que satisfacer a los visigodos antes de reemprender las relaciones diplomáticas, o si fue la Iglesia la que intervino en la solución del conflicto, dado que los dos pueblos eran arrianos ${ }^{19}$. De hecho, la hostilidad visigoda hacia los vándalos fue manifiesta en los años siguientes coincidiendo con el reinado de Teodorico II.

Este rey contrasta con su progenitor por su actitud aliancista favorable a Roma en lugar de hacerlo con los pueblos germánicos. Posiblemente influyó de manera decisiva en este cambio la formación latina que en su juventud habia recibido directamente del noble patricio galo, Avito, suegro de Sidonio Apolinar. Su relación con Avito superó la normal de un maestro con su alumno para convertirse en una verdadera amistad que, en su día (9 de junio del a. 455), ayudaría a Avito a obtener la púrpura imperial al contar con el apoyo de los poderosos visigodos. Por otra parte Avito encontró siempre en Teodorico II un aliado fiel, aún cuando los visigodos ya no debían tener ningún compromiso militar con la administración central fuera del área aquitana que les había sido originariamente asignada. Tal vez a instancias de esta amistad, en el a.

res con su "suegro", sino que fue a consolidar su amistad con uno de los monarcas más poderosos y que, también, podía ser más peligroso.

${ }_{17}$ Para solicitar su ayuda, Honorio tuvo que enviarle un embajador muy especial, el Prefecto de Pretorio de las Galias, Avito. Es indiscutible que Teodorico I ya no consideraba obligación suya, como lo había sido en el 422, acudir al encuentro de los hunos y que si lo hizo fue por la propia salvaguardia de su reino amenazado por un enemigo ancestral.

${ }^{18}$ Cfr. Chr. Courtois, "Rapports...", págs. 449-507.

19 A. Dopsch, (Fundamentos económicos y sociales de la cultura europea. De César a Carlomagno. Traducción de J. Rovira Armengol, Madrid, 1982 pág. 333) recoge las siguientes palabras: "la Iglesia supo (...) adaptar su situación conciliadora al derecho germánico, entregando a los delicuentes que acudian a su amparo cuando el ofendido, o sus parientes, prometian renunciar a la venganza si se les hacía efectivo el "wergeld". 
455, Teodorico ll envió un ejército a la Tarraconense, al mando de su hermano Frederico, para pacificarla de las sublevaciones bagaúdicas y de los ataques continuos del rey suevo Requiario. Parece claro que no le interesaban nada los lazos diplomáticos anudados por su parte porque, según cuenta Hidacio (Chron. a. 456, 170), fue «fiel al Imperio romano» y firmó un tratado contra los suevos y los vándalos sin importarle que el rey de los primeros, Requiario, fuera el marido de su hermana. Los suevos fueron derrotados por Teodorico II en persona quien primero tomó Braga, la capital, y después sitió Mérida, donde el rey Requiario falleció en el a. 456 siguiendo a su muerte un largo período de anarquia y guerras civiles. Es posible que en el ataque al reino suevo también intervinieran, junto a los visigodos, un contingente de burgundios ${ }^{20}$. Por la misma fecha Teodorico recibió la visita del tribuno Hesichyus ${ }^{21}$ que le informó de la derrota de una «multitud» de vándalos en Córcega frente a Ricimer (Hidacio, Chron., 177).

En los primeros días de abril del a. 457, cuando se encontraba todavia en Hispania, Teodorico recibió la noticia de la deposición y muerte de Avito (Gregorio de Tours, Hist. Franc. II, 11) con lo cual debió considerar concluida su fidelidad hacia el Imperio. Ante la elección del nuevo emperador Mayoriano, cuya legitimidad no reconoció hasta el a. 459, prefirió controlar la situación desde su reino galo pero, al mismo tiempo, también quiso dar el golpe de gracia al poderío suevo en la Península, para lo que dejó a parte de su ejército asediando la región palentina. Sin embargo la traición de su cliente y segundo comandante. Agiulfo, que se proclamó rey (Hidacio, Chron. 187; Jordanes, Getica, XLIV, 234), permitió la recuperación de los suevos.

La muerte de Avito trajo consigo un drástico cambio en la situación diplomática del reino visigodo pues, aunque aparentemente Teodorico II mantuvo relaciones cordiales con los emperadores Mayoriano y Libio Severo, con quien en realidad concluía los pactos era con el patricio Ricimer, por cuyas venas corría tanto sangre visigoda, al ser nieto de Walia, como sueva, con lo que se retornaba a las alianzas con germanos de tiempos de Teodorico I. Por otra parte, la monarquía tolosana iba dando cada vez mayores signos de independencia. Teodorico II pactó con Mapág. 46.

${ }^{20}$ Cfr. W. ReInhart, Historia general del reino hispánico de los suevos, Madrid 1952 ,

${ }^{21}$ Para todo este asunto consultar Chr. Courtois (Les Vandales..., y, en concreto, la pág. 186). Hay que resaltar el hecho de que el gobierno romano quisiera informar a Teodorico del hecho por medio de un alto magistrado, un tribuno, con lo que evidentemente se pretendia consolidar el tratado firmado común contra los vándalos en 445. 
yoriano, aunque también lo hizo obligado por la necesidad, justo es decirlo pues, el no hacerlo, hubiera engrandecido aún más al vándalo Genserico, quien pretendia sentar en el trono de Roma -invocando derechos dinásticos - a Olibrio, noble romano casado con una hija de Valentiniano III, y a quienes tenía prisioneros. El emperador Mayoriano pretendió restaurar la fortaleza imperial en Occidente y, ante el desorden sucesorio existente en el reino suevo que estaba perjudicando la vida de los provinciales, permitió nuevas intervenciones militares godas en los a. 458 y 459 , realizadas en nombre del Imperio ${ }^{22}$, pero dirigidas por los condes godos Cyrila y Sunierico, gracias a las cuales Teodorico II pudo limitar los avances suevos.

Durante el reinado de Mayoriano (a. 457-461), la actividad expansionista e independentista de los germanos quedó contenida y el Imperio de Occidente logró, tal vez por última vez, el respeto de éstos. El nuevo Emperador restableció la autoridad imperial en los territorios de la prefectura de las Galias y la Tarraconense conteniendo las pretensiones territoriales de visigodos y suevos; también concluyó un tratado de federación con los burgundios (Sidonio, Carm. V, 564-573), y mandó construir una escuadra con la que preparó una gran empresa marítima contra los vándalos en mayo del a. 460 que, pese al esmero con que fue organizada, resultó un fracaso para Roma. A raíz de ella Genserico obtuvo el dominio de las islas del Mediterráneo Occidental, con lo que esta parte del Imperio quedó definitivamente aislada de Oriente por vía marítima. El rey visigodo también quiso participar en el control del Mar y, en el a. 462 tomó Narbona y alcanzó el Mediterráneo. De nuevo se fortalecían las relaciones entre los vándalos y los visigodos sin que los burgundios hicieran nada por debilitarlas, sino más bien al contrario, aprovecharan a su vez para extender su territorio.

Tras el asesinato de Mayoriano en 461, fue la falta de interés de Ricimer por todo lo que no fuera consolidar su situación en Italia lo que facilitó a Teodorico II, tal y como hemos visto, la expansión territorial por el sur de la Galia y sus contactos con los vándalos, señores por entonces del Mediterráneo Occidental. Los territorios hispanos quedadon aislados y a merced de los poderosos visigodos. Por eso resulta congruente que

22 Cfr. L. Garcia Moreno, “Mérida y el reino..." págs. 227-240. Cuenta Hidacio (Chron 197) que una delegación romano-visigoda encabezada por Sunierico y Nepociano anunció a los suevos la paz concertada entre Teodorico y Mayoriano, tal vez como previo aviso a las futuras invasiones, permitidas por Roma, que los suevos habrian de sufrir (Cfr. R. Gibert: "El reino visigodo y el particularismo español”, Estudios Visigóticos /, Rama-Madrid 1956, pág. 23). 
entre el año 462 y 463 , la aristocracia galaicorromana dirigiese una embajada a Teodorico II a su propia capital, Tolosa, para pedirle ayuda frente a los suevos que seguian sumidos en discordias internas. El rey visigodo intervino entonces en la elección de un nuevo monarca suevo, Remismundo, a quien hizo su cliente ${ }^{23}$ y cuya actuación quedó en el futuro limitada por el control visigodo. Merced al apoyo de los vecinos del reino tolosano, Remismundo consiguió imponerse sobre su adversario Frumario y convertirse en rey de todos los suevos. Hidacio cuenta (Chron. 140, 226) que, en agradecimiento, mandó a Toulouse una embajada portadora de regalos con la que inició una serie de frecuentes contactos diplomáticos con la corte de Teodorico II, que Remismundo encomendó al duque Cyrila. En el a. 464, el propio rey suevo acudió a Toulouse para pedir la mano de una noble visigoda de la familia real ${ }^{24}$, con lo que pasó así a convertirse en "hijo de armas" del rey Teodorico. Una vez más, las monarquías sueva y visigoda quedaron comprometidas con vínculos familiares, y esta última aseguró su predominio a ambos lados de los Pirineos. La injerencia visigoda llegó al extremo de intervenir también en cuestiones religiosas y, en el a. 465, Teodorico envió a Braccara Augusta a un obispo arriano, Ayax, para que predicara entre los suevos la religión oficial del reino visigodo ${ }^{25}$.

Mientras, el vándalo Genserico consiguió en el a. 462 que el emperador de Oriente, León I, renunciara a inmiscuirse en los asuntos de su nuevo colega de Occidente, Libio Severo ${ }^{26}$.

${ }^{23}$ Cfr. L. Garcia Moreno, Historia de España Visigoda, Madrid, Cátedra, 1989, pág. 66.

${ }^{24} \mathrm{H}$ IDACIO, Chron. 140, 226.

${ }^{25}$ Cfr. E. A. Thompson, "The conversion of the Spanish Suevi to Catholicism", E. James: Visigothic Spain. New Approaches. Oxford 1980, págs. 80-81; e HIDACIO, Chron, 232.

26 Es notoria la admiración que se sentía en estas fechas tanto por el rey vándalo, como por el visigodo, sobre todo en la corte bizantina. Años antes (455) Sidonio habia dejado una apasionada descripción de Teodorico II (Epist. I, II) en la que elogiaba sus cualidades físicas y morales: la modestia, la sencillez de costumbres, su habilidad y rapidez en la caza, el equilibrio y la mesura de sus emociones etc., y en otro lugar (Carm. XXIII, 71 y ss.) reconocía que, como jefe, era incluso superior a su padre Teodorico I, y le llamó "Romanae columen salusque gentis". Un siglo después Jordanes (Getica, 168) admiró igualmente la personalidad del vándalo Genserico, aunque ignoramos la fuente de dónde pudo tomar la descripción: “Erat (...) animo profundus, sermone rarus, luxuriae contemptor, ira turbidus, habendi cupidus, ad sollicitandas gentes providentissimus, semina contentionum iacere, odia miscere paratus". Procopio sintió admiración por ambos y les consideró los mejores de los reyes góticos (Bell. Goth. III, 1, 4). Cfr. para este tema, Fr. Giunta, "I vandali

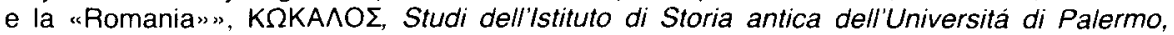
II,1,1956, págs. 34-36. 
Por las mismas fechas entró un nuevo pueblo germánico en el juego político de los visigodos, los francos salios de Childerico (Gregorio de Tours, Hist. Franc. II, 18). Éstos habían pactado con el general Egidio, que gobernaba de forma prácticamente independiente el norte de la Galia, para contener a los visigodos en su frontera septentrional, como así lo hicieron tras derrotarles en el a. 463 en las cercanias de Orléans. Hidacio, sin embargo, consideró (Chron. 218) que el enfrentamiento de los visigodos contra Egidio y los francos se hizo en nombre de la amistad que unía a aquéllos con Libio Severo. Por las mismas fechas, y según cuenta el obispo de Tours, los sajones invadieron el territorio de Egidio y el de los visigodos, pero ésta, en realidad, no fue más que una de las invasiones períodicas que los sajones venían realizando desde el siglo III ${ }^{27}$ por el Ilamado Litus Saxonicum.

En el a. 466 Teodorico II fue asesinado y sucedido por su hermano Eurico quien, "por la enorme prisa que tuvo para sucederle hizo pesar sobre él violentas sospechas" ("cui frater Eurichus praecupida festinatione succedens sceva suspicione pulsatus est") (Jordanes, Get. XLV, 235). El nuevo rey se encontraba totalmente desvinculado del Emperador de Occidente, y su arraigado sentimiento de independencia se plasmó, entre otras cosas, en la tendencia a formar coaliciones con otros pueblos germánicos ${ }^{28}$. Al año siguiente (467) mandó una embajada a Genserico para hacer frente común ante el Imperio y evitar el restablecimiento de la autoridad imperial en el norte de África. Parece claro que ya nada quedaban de las viejas deudas familiares por la afrenta cometida contra su hermana en el a. 455, y que no se puede hablar, como repetidamente ha hecho Courtois, de hostilidad tradicional entre los dos pueblos. Genserico, que seguía controlando el Mediterráneo Occidental, animó a su aliado a ocupar más puertos costeros galos, como así hizo con Arles (a. 471) y Marsella (a. 473). También mandó Eurico legados al suevo Remismundo pero, según cuenta Hidacio (Chron. 238), éste los devolvió en seguida a Toulouse y, en cambio, mandó sus propias embajadas al Emperador (a. 468-469). Una vez muerto Teodorico II, Remismundo se consideró desligado de sus antiguos vínculos de fidelidad con el rey visigodo ${ }^{29}$. Finalmente, informa Sidonio (Epist. $\mathrm{V}, 6,2 ; 7,1$ ) que tras la caida del emperador Glycerio (a. 474), se iniciaron contactos entre visigodos y burgundios para la realización de nuevas alianzas, si bien es

${ }^{27} \mathrm{~F}$. Lot, "Les migrations saxones en Gaule et en Grande-Bretagne du III au V $\mathrm{V}^{e}$.", Revue Historique, CXIX, 1915, págs. 1-40.

${ }_{28}$ E. STEIN, Histoire du bas-Empire, 1959, vol. I, pág. 388.

29 R. GiBert, obra citada, nota 20, pág. 35. 
cierto que éstas venían de antiguo y se habian materializado con el matrimonio de Eurico con la princesa Ragnahilde la cual ya estaba en la corte visigoda, al menos en el a. 466-67, según se deduce de la mencionada correspondencia de Sidonio Apolinar ${ }^{30}$. A partir del 468 Eurico ocupó en las Galias la Turena y el Berry, aunque no pudo superar la orilla derecha del Loira defendida por los francos. También por la misma fecha, rota como hemos visto la alianza con los suevos, les tomó Mérida, limitando definitivamente su territorio de expansión. En este año concluye la Crónica de Hidacio, nuestra principal fuente de información para las relaciones entre visigodos y suevos, y no disponemos de más noticias de enfrentamientos entre ambos pueblos. Es posible que, en realidad, no los hubiera porque, como dice García Moreno ${ }^{31}$ "de haber existido problemas serios habrian quedado reflejados en la Cronica Caesaraugustana". Entre los a. 470 y 475 Eurico centró su atención en dos zonas que todavia permanecian romanas, la Tarraconense y la Auvernia, pero que estaban incomunicadas de Italia a consecuencia del control vándalo en el Mediterráneo. Ya nada quedaba de la antigua fidelidad visigoda a Roma y así lo recuerda Sidonio cuando se refiere (Epist. VII, 6) a la ruptura con el "antiguo tratado" (foedus priscum). Los romanos, al menos los que vivían en territorios gobernados por germanos, estaban asumiendo como un hecho consumado que éstos disfrutaban de plena independencia, y no sólo de una cierta autonomía con respecto al gobierno central. También lo vio así el nuevo emperador, Julio Nepote, porque a partir de junio del a. 474 , envió a Toulouse reiteradas embajadas intentando recuperar para Roma las ciudades de Arles y Marsella, a cambio del reconocimiento de la soberanía del rey visigodo sobre el resto de los territorios ocupados. Eurico debió quedar agradecido por el trato y cuando, en el mes de octubre del a. 475, Nepote fue destituido llegó a mandar una embajada al emperador de Oriente, Zenón, rogándole que repusiera en el trono a su antiguo aliado.

Después del a. 476 Eurico emprendió con éxito la guerra contra los burgundios (Jordanes, Get., XLVII, 244) y consiguió convertirse, junto con el rey vándalo, en señor soberano de Occidente, No obstante, el futuro del reino visigodo ya iniciaba un perfil precario cuando otros reinos rivales, ahora menos poderosos, comenzaron a cercarlo buscando su estran-

${ }^{30}$ Sidonio APOLINAR, Epistulae, IV, 8, escribe a su amigo Evodius notificándole el envio de un poema de doce versos que aquél pensaba hacer grabar sobre un vaso que iba a regalar a la reina

${ }^{31}$ Cfr. L. Garcia Moreno, "Mérida y el reino...", pág. 233. 
gulamiento. Al norte estaban los francos, al noreste los alamanes y al sureste los burgundios.

En el a. 484 Alarico II accedió al trono de Toulose, y su reinado supuso el punto final del predominio visigodo en Occidente, que fue heredado por los francos de Clodoveo en la Galia y por los ostrogodos en Italia. Su rey, Teodorico el Grande, repitió -ahora ya con pleno derecho- la política aliancista trazada por su homónimo en Toulouse años antes, para lo cual casó a una de sus hijas, Areaagne, con el visigodo Alarico; a otra, Theodegoto, con Sigismundo, heredero del trono burgundio; y a su hermana Amalafrida, con el vándalo Trasamundo (hacia el a. 500). Años después, en 508, reforzó su amistad con los visigodos de los que era regente, (aunque tal vez deberiamos hablar mejor de predominio sobre ellos), casando a su hija Amalaswinta con Eutarico, un noble Amalo que habia llegado con su padre en secreto a la corte de Tolosa al comienzo del reinado de Teodorico $I$.

Los incidentes diplomáticos entre los francos salios y los visigodos comenzaron en el a. 486 y continuaron con carácter bélico en los posteriores. Clodoveo fue venciendo y aliándose con los pueblos vecinos de los visigodos (alamanes, burgundios y habitantes del Tractus Armoricanus) y, a la vez, infligiendo a aquéllos continuas derrotas militares. Los godos vieron cómo, tras perder puestos fronterizos, como las ciudades de Saintes y Tours, el territorio de su reino galo en la cuenca media del Garona iba quedando progresivamente más mermado, y fue posiblemente la evidencia de la supremacía franca lo que les hizo volver su atención a Hispania e iniciar unas penetraciones masivas de gente entre el a. 494 y 497 , recogidas en la Chronica Caesaraugustana ${ }^{32}$. Mientras, en la Galia, la situación con los francos se hacía cada vez más tirante y peligrosa al no contentarse éstos con el asedio de las fronteras y comenzar la penetración en el corazón del reino con la ocupación de algunas de las ciudades más importantes, como Burdeos, en el a. 498. Ello obligó a que Teodorico el Grande, "suegro" de Alarico ${ }^{33}$, se viera obligado a

${ }^{32}$ Tradicionalmente se venía admitiendo la tesis de Ramón d'Abadal que defendía que se trataba de una inmigración popular ("A propos du legs visigothique en Espagne", Caratteri del secoio VII in Occidente, Settimane de Spoleto, 1958, pág. 545); pero, más recientemente García Moreno ( Mérida..." pág. 238) ha sostenido la opinión de que se trataba de la entrada de tropas para controlar el valle del Ebro y acabar con las últimas resistencias indígenas.

33 Remito a lo que decíamos más arriba (nota 16) acerca de los vínculos de parentesco contraidos a través del matrimonio entre los pueblos germánicos. Sin embargo, en la intervención de Teodorico el Grande debemos ver algo más que una simple preocupación familiar. Parece claro que la dinastia de los Amalos se consideraba la legítima depositaria de 
intervenir y, a partir del a. 502, mediara una abundante correspondencia, de la que da cuenta Cassiodoro en sus Variae, para que firmaran la paz. Parece que hubo un pequeño atisbo de entendimiento tras una entrevista que ambos reyes, Clodoveo y Alarico, mantuvieron en una isla de Loira (Gregorio de Tours, Hist. Franc., II, 35), pero la supremacía franca sobre los demás pueblos germánicos de la Galia, alamanes, francos ripuarios, alanos y burgundios, era demasiado evidente como para que esta entente no supusiera más que un retraso al desenlace inevitable que se produciría en la batalla de Vouillé del a. 507. Llama la atención que los vándalos no acudieran en ayuda de sus antiguos aliados, y más cuando tenemos noticias de que se mantuvieron los contactos entre ambos ${ }^{34}$. Posiblemente Alarico II, o bien esperaba su ayuda militar, y de ahi su indecisión a entrar en el conflicto al que, según Procopio (De Bello Gothico, I, XII, 36-39), se vio obligado por resolución de su propio ejército; o bien era consciente de la falta de preparación de sus tropas, reprochada por Teodorico el Grande (Cassiodoro, Variae, VIII, 3), por lo que procuró eludir un enfrentamiento de tal magnitud. La fulminante derrota de Vouillé, no sólo acabó con la vida del rey, terminó también con una fase importante de la historia política de los visigodos y obligó a que el grueso de la gens gothorum (exceptuando los que quedaron en la Septimania) tuviera que cruzar definitivamente los Pirineos.

la soberanía del reino de Tolosa, habida cuenta de que en los días de Hermanarico los visigodos habian estado sometidos a los ostrogodos. Hubo un primer intento de recuperarla cuando Berimsundo, bisnieto de Hermanarico, que se hallaba en Tolosa a la muerte de Walia, pretendió ser él el elegido (Jordanes, Getica, XXXIII). Fracasado este, el matrimonio de Alarico Il con una hija del rey Amalo ofreció una segunda ocasión, mucho más fructífera, a juzgar por el significativo nombre que recibió el niño nacido de esta unión: Amalarico.

${ }^{34}$ Gregorio de Tours (Hist. Franc. II, 3) cuenta cómo Hunerico exiló al obispo católico Eugenio a la ciudad de Albi, lo cual sólo era posible en caso de que los visigodos las aceptaran alli. Tambien sabemos que el hijo natural de Alarico ll. Gesaleico, perseguido por el ostrogodo Teodorico que defendia la sucesión de su nieto Amalarico bajo su regencia, encontró asilo político en África gracias a la protección de Trasamundo. Teodorico protestó al rey vándalo, y Trasamundo no tuvo más remedio que ofrecerle una satisfacción (Cassiodoro, Variae, V, 43 y 44). 